\title{
Identidade territorial e visibilidade midiática: o artesanato no Caderno Quarta Colônia
}

\author{
Territorial identity and media visibility: the handicraft in the Caderno \\ Quarta Colônia
Identidad territorial y visibilidad de mediática: la artesanía en el Caderno Quarta Colônia

\author{
Carolina luva de Mello ${ }^{1}$ \\ José Marcos Froehlich ${ }^{1}$
}

Recebido em 26/06/2018; revisado e aprovado em 12/11/2018; aceito em 29/11/2018 DOI: http://dx.doi.org/10.20435/inter.v20i3.2059

\begin{abstract}
Resumo: O território Quarta Colônia, RS, vem atuando para consolidar uma imagem identitária coletiva. A elaboração e publicação do Caderno Quarta Colônia, visando dar visibilidade midiática às ações e potencialidades do território, é constituinte do discurso do desenvolvimento naquele contexto. Dada à relevância contemporânea do artesanato, propiciada por seus atributos simbólicos, este artigo tem por objetivo analisar, a partir de pesquisa documental, como o tema foi inserido nas narrativas de projeção identitária promovidas pelos 225 fascículos publicados no Caderno Quarta Colônia. Flagra-se, nesse sentido, a seletividade presente nas enunciações do discurso do desenvolvimento no território.
\end{abstract}

Palavras-chaves: artesanato; identidade territorial; visibilidade midiática; Caderno Quarta Colônia.

Abstract: The Quarta Colônia territory, RS, has been working to consolidate a collective identity image. The elaboration and publication of the Caderno Quarta Colônia, aiming to give a media visibility to the actions and potentialities of the territory, is a constituent of the discourse of development in that context. Given the contemporary relevance of the handicraft, propitiated by its symbolic attributes, this article aims to analyze, from a documentary research, how the theme was inserted in the identity projection narratives promoted by the 225 fascicles published in the Caderno Quarta Colônia. The selectivity present in the enunciations of the development discourse in the territory is flagged in this sense

Keywords: handicraft; territorial identity; media visibility; Caderno Quarta Colônia.

Resumen: El territorio Quarta Colônia, RS, viene actuando para consolidar una imagen identitaria colectiva. La elaboración y publicación del Caderno Quarta Colônia, visando dar visibilidad mediática a las acciones y potencialidades del territorio, es constituyente del discurso del desarrollo en aquel contexto. Dada la relevancia contemporánea de la artesanía, propiciada por sus atributos simbólicos, este artículo tiene por objetivo analizar, a partir de la investigación documental, como el tema fue insertado en las narrativas de proyección identitaria promovidas por los 225 fascículos publicados en el Caderno Quarta Colônia. En este sentido se separa la selectividad presente en las enunciaciones del discurso del desarrollo en el territorio.

Palabras claves: artesanía; identidad territorial; visibilidad mediática; Caderno Quarta Colônia.

\section{INTRODUÇÃO}

Os processos universalizantes das novas tecnologias de informação e de comunicação possibilitaram a troca de experiências e visões de mundo entre civilizações e culturas até então distantes. Desse modo, não se trata mais de considerar o local como oposição ao global, mas como processos indissociáveis de globalização e territorialização (MELLO, 2016). Assim, cabe visualizar o território² como um campo de disputa onde os atores buscam, por intermédio de

\footnotetext{
${ }^{1}$ Universidade Federal de Santa Maria (UFSM), Santa Maria, Rio Grande do Sul, Brasil.

${ }^{2}$ A perspectiva de território utilizada neste artigo é a relacional, "na qual o poder é a chave - em toda relação circula o poder que não é nem possuído nem adquirido, mas simplesmente exercido" (RAFFESTIN, 1993, p. 7).
} 
variados recursos materiais e culturais, imprimirem sentidos e interpretações, tomarem posições, produzirem e legitimarem consensos favoráveis a si (BRANDÃO, 2007).

Na contemporaneidade, os atores sociais buscam promover a construção de uma imagem identitária coletiva para o território, tornando sua projeção um objetivo estratégico e expressão de disputa nas narrativas que compõem o discurso do desenvolvimento ${ }^{3}$ (CASTELLS, 1999; BAUMAN, 2008; BRANDÃO, 2007; ESCOBAR, 1995). Em uma perspectiva antropológica, a identidade consiste no pertencimento a um grupo que compartilha signos e significados reconhecidos por todos e reivindicados na interação com a alteridade. Portanto a imagem identitária coletiva do território é composta pelo que Barth (2000) denominou de sinais diacríticos, elementos identificadores de um grupo atribuídos e reconhecidos reciprocamente pelos seus membros.

Nesse contexto, o artesanato produzido nos territórios é passível de mobilização e agenciamento nas estratégias de construção e projeção identitária. Considera-se artesanato como sendo o produto resultante da transformação da matéria-prima, com predominância manual, por um indivíduo que detém o domínio integral de uma ou mais técnicas previamente conceituadas, aliando criatividade, habilidade e valor cultural (PROGRAMA DO ARTESANATO BRASILEIRO [PAB], 2012). A expansão da produção industrial ao longo do século XX fez com que muitos acreditassem no desaparecimento progressivo da produção artesanal de bens (RIOS, 1969). Porém, contrariando os prognósticos negativos, são vários os indícios de que o lugar do artesanato na sociedade contemporânea está se expandindo, especialmente em razão dos atributos simbólicos que permite acionar (PAZ, 2006; BORGES, 2011; MELLO, 2016).

A Quarta Colônia, localizada no centro geográfico do Estado do Rio Grande do Sul (RS), é o foco analítico deste artigo, sendo um território que há mais de século passou a ser composto por imigrantes não ibéricos, principalmente italianos, que trouxeram consigo o costume do fazer artesanal em sua italianidade (ZANINI, 2006; TEDESCO, 2005). Desde o início da década de 1990, o Consórcio de Desenvolvimento Sustentável da Quarta Colônia (CONDESUS) tem promovido ações com o objetivo de consolidar a construção de uma imagem identitária coletiva para o território (FROEHLICH, 2002; ZANINI, 2006; VENDRUSCOLO, 2009; FROEHLICH; KEGLER, 2011).

Entre as ações promovidas pelo CONDESUS, destaca-se a elaboração do Caderno Quarta Colônia, publicado semanalmente entre 2006 e 2011 como encarte no jornal Diário de Santa Maria $^{4}$ com o objetivo de divulgar os acontecimentos e potencialidades do território para um público externo (VENDRUSCOLO et al., 2008). Ressalta-se que o Caderno foi uma importante ação de construção e projeção identitária do território, pois a mídia proporciona visibilidade privilegiada às ações sociais e possui capacidade de legitimar indivíduos e instituições mediante a produção e circulação de mensagens e imagens que acionam e organizam redes de sentidos (THOMPSON, 2008; BARICHELLO, 2006).

A visibilidade midiática contribui para enfatizar características específicas, promover certos produtos e evidenciar determinados saberes de um grupo que almeja reconhecimento, projetando no espaço público elementos constitutivos de sua identidade territorial (FROEHLICH;

\footnotetext{
${ }^{3}$ Entende-se por discurso "um modo de construir sentidos que influencia e organiza tanto nossas ações quanto a concepção que temos de nós mesmos" (HALL, 2006, p. 50). Já o desenvolvimento como discurso "surgiu no começo do período após a Segunda Guerra Mundial, tendo raízes em processos históricos mais profundos da modernidade e do capitalismo" (ESCOBAR, 2005, p. 18, tradução nossa).

${ }^{4} \mathrm{Na}$ época jornal da Rede Brasil Sul de Comunicações (RBS), corporação de mídia afiliada da Rede Globo, com circulação em 36 municípios da região Central e Fronteira-Oeste do RS.
} 
KEGLER, 2011). É, portanto, um processo envolto por relações de poder, pois alguns elementos identificadores são selecionados para serem colocados em evidência, em detrimento de outros. Nesse contexto, devido à relevância contemporânea do artesanato propiciada por seus atributos simbólicos, faz-se relevante observar como ele foi inserido nas narrativas midiáticas de construção e projeção identitária promovidas pelo Caderno Quarta Colônia. Para isso, a partir de uma perspectiva interpretativista foi realizada uma pesquisa documental nos 225 fascículos publicados do Caderno, analisando-se, nas reportagens que faziam menção ao artesanato, como se deu o seu acionamento como sinal diacrítico para a composição de uma imagem identitária coletiva para o território.

\section{IDENTIDADE, TERRITÓRIO E VISIBILIDADE MIDIÁTICA}

A expansão da globalização facilitou a massificação de processos econômicos e simbólicos a partir da criação de um imaginário coletivo 'internacional popular' (ORTIZ, 2013). Porém, em paralelo e como que em um movimento reativo, a preocupação com as identidades sociais passou a permear discussões em diversas áreas do conhecimento (ALBAGLI, 2004).

As identidades "emergem no interior do jogo de modalidades específicas de poder e são, assim, mais o produto da marcação da diferença e da exclusão do que o signo de uma unidade idêntica, naturalmente constituída" (HALL, 2006, p. 109). Permanentes lutas semânticas são travadas com o intuito de neutralizar, perturbar ou alterar o significado das narrativas em disputa pela identidade (CASTELLS, 1999; CANCLINI, 2013).

Entre as diversas produções identitárias contemporâneas, aquela catalisada pela variável territorial tem se destacado devido à importância que Ihe tem sido atribuída como promotora de estratégias que se tecem em nome do desenvolvimento (ABRAMOVAY, 2003; FAVARETO, 2010; FROEHLICH, 2012). A construção de uma imagem identitária coletiva funciona como um amálgama social e, por vezes, como elemento catalisador de ações e sinergias capazes de promover sentidos acerca do território e fomentar atividades socioeconômicas e socioculturais baseadas na diferenciação (PECQUEUR, 2005).

As identidades territoriais podem servir de repertório ao qual se recorre e onde se selecionam, à medida das necessidades, sinais diacríticos a serem acionados nas narrativas de construção e projeção identitárias (CUNHA, 1986). Os sinais diacríticos são compostos por elementos identificadores que os próprios atores consideram como significativos pelos seus critérios de pertencimento (BARTH, 2000), sendo um importante processo de afirmação do grupo e garantindo sua singularidade frente aos demais (CUNHA, 1986). São, acima de tudo, objetos de uma (re)interpretação da história do território, selecionados e acionados a partir de relações de poder.

A perspectiva de território utilizada neste artigo é a relacional, para a qual o poder ${ }^{5}$ está no centro da análise e a territorialidade é formada pelas relações sociais que se estabelecem no interior dos territórios (RAFFESTIN, 1993; HAESBAERT, 1997). Nesse sentido, além da dimensão de caráter político-disciplinar, o território envolve também uma dimensão simbólica, "através de uma identidade territorial atribuída pelos grupos sociais, como forma de 'controle simbólico' sobre o espaço onde vivem" (HAESBAERT, 1997, p. 42). A territorialidade, portanto, corresponde à "tentativa, por um indivíduo ou grupo, de atingir/afetar, influenciar ou controlar pessoas, fenômenos e relacionamentos, pela delimitação e afirmação do controle sobre [o território]" (SACK, 1986, p. 265).

\footnotetext{
${ }^{5}$ No sentido que lhe dá Foucault (1990; 1995), qual seja, da capacidade de agir sobre as ações de outros.
} 
O poder encontra-se na base de todas as relações sociais: é a chave da inteligibilidade do espaço social, como mecanismo condutor e instável, onipresente, reproduzido a cada momento na multiplicidade e no entrecruzamento das relações (FROEHLICH, 2015). É o poder e sua lógica relacional que delimita o modo como os recortes de visibilidade são operacionalizados, evidenciando determinadas características em detrimento de outras para atingir objetivos previamente estabelecidos (PIPPI, 2012; FROEHLICH, 2015).

Além disso, destaca-se que, na sociedade contemporânea, todos os fenômenos estão sujeitos, em graus e formas variáveis, à influência da mídia, sendo a midiatização ${ }^{6}$ inerente aos processos sociais (VERÓN, 1997; CASTELLS, 1999; SODRÉ, 2002; KEGLER, 2011). Nesse contexto, enquanto condicionante fundamental da existência pública, a visibilidade midiática contribui para moldar a percepção dos atores sobre a territorialidade e transforma a constituição simbólica dos territórios ao (res)significar os elementos identificadores a ele relacionados (FROEHLICH; KEGLER, 2011).

Assim, consumir informações tornou-se o primeiro passo no caminho do consumo de bens e serviços, de modo que produzir conteúdo midiático se tornou uma relevante maneira de exercício do poder (THOMPSON, 2008). Nesse contexto, a mídia passa a ter um papel central e estruturante, cuja potencialidade em legitimar a identidade dos territórios é mediada pela seletividade das mensagens e imagens circulantes que terão visibilidade (FROEHLICH; KEGLER, 2011). A projeção dos elementos identificadores do território objetiva sensibilizar a audiência externa para que o consuma, seja como informação, através de sua experimentação, ou como produto que o qualifique (PIPPI, 2012; FROEHLICH, 2015). Portanto a visibilidade midiática pode auxiliar os atores sociais na construção de uma imagem identitária coletiva para o território, cuja projeção se faz relevante para as estratégias contemporâneas de desenvolvimento territorial baseadas na diferenciação identitária.

\section{CONSTRUÇÃO E PROJEÇÃO IDENTITÁRIA NA QUARTA COLÔNIA}

Localizado no centro geográfico do Rio Grande do Sul, o território hoje conhecido como Quarta Colônia conta com uma população total aproximada de 60 mil habitantes $^{7}$ (IBGE, 2014) e abriga nove municípios anteriormente pertencentes a duas colônias oficiais do Governo Imperial. Os municípios de Agudo, Restinga Sêca, e partes de Nova Palma e Dona Francisca, faziam parte da Colônia Alemã de Santo Ângelo. Já os municípios de Silveira Martins, Ivorá, Faxinal do Soturno, Pinhal Grande, São João do Polêsine, e partes de Nova Palma e Dona Francisca, pertenciam à Colônia Italiana de Silveira Martins (Figura 1). Desse modo, há clara predominância italiana entre as famílias de imigrantes no atual território da Quarta Colônia, apesar da forte influência da colonização alemã .

\footnotetext{
${ }^{6}$ Fenômeno de mídia que ultrapassa os meios enquanto instrumentalidades, sendo resultante da articulação entre os dispositivos tecnológicos e as condições específicas de produção e de recepção (VERÓN, 1997).

${ }^{7}$ Os municípios com maiores contingentes populacionais são Agudo e Restinga Sêca, que possuem população acima de 15 mil habitantes. Já os menores são Ivorá e Silveira Martins, com população inferior a três mil habitantes (ATLAS DO DESENVOLVIMENTO HUMANO NO BRASIL, 2013).

${ }^{8}$ A formação do território da Quarta Colônia também recebeu influências dos imigrantes açorianos e dos escravos negros que, após a abolição em 1888, formaram diversos núcleos quilombolas nas redondezas (NEUMANN, 2003).
} 
Figura 1 - Mapa da Quarta Colônia

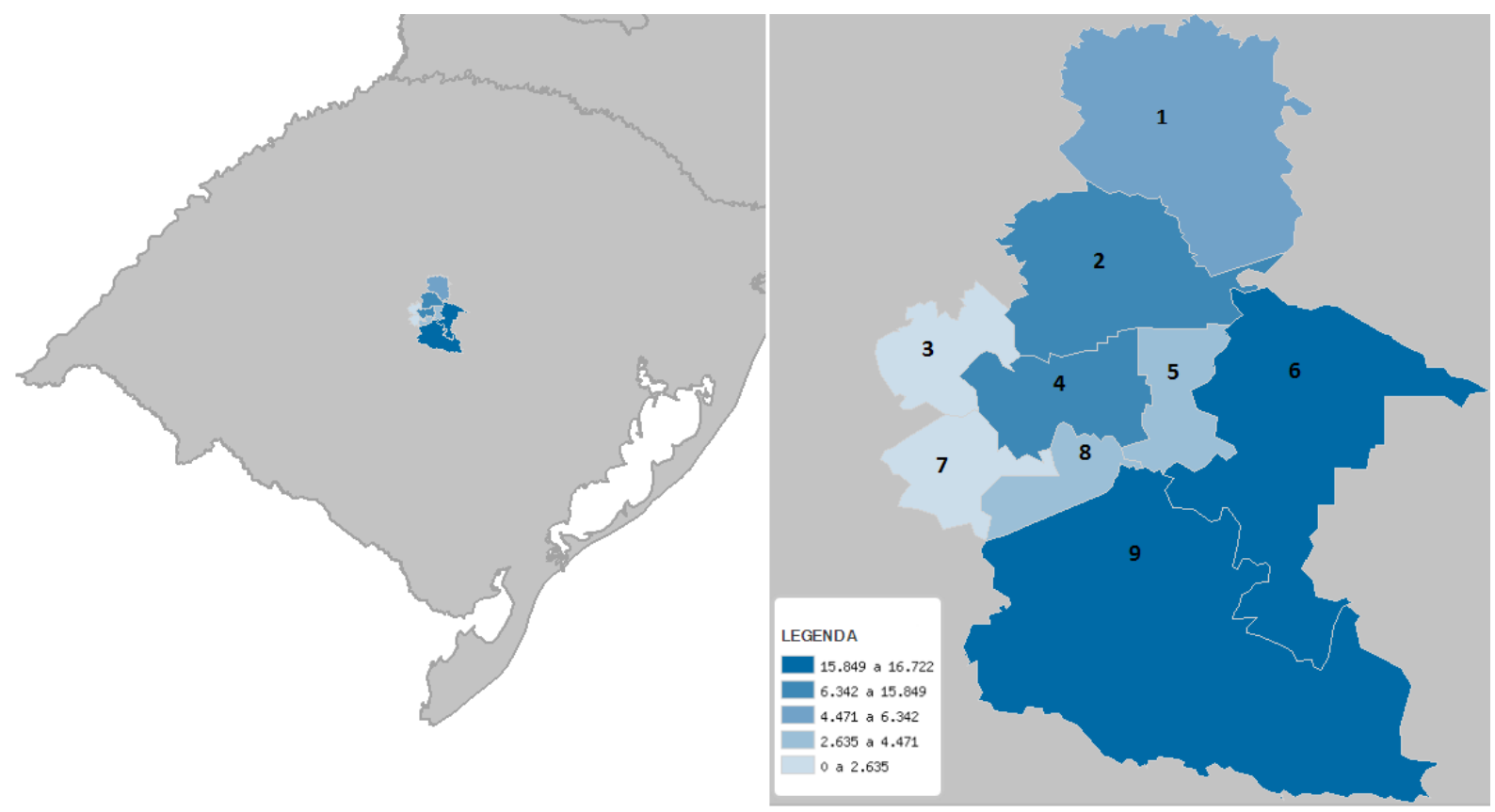

Fonte: Adaptado de Atlas do Desenvolvimento Humano no Brasil (2013).

Legenda: 1: Pinhal Grande; 2: Nova Palma; 3: Ivorá; 4: Faxinal do Soturno; 5: Dona Francisca; 6: Agudo; 7: Silveira Martins; 8: São João do Polêsine; 9: Restinga Sêca.

Em 1882, o Governo Imperial decretou a autonomia da Colônia de Silveira Martins e, por meio de um decreto promulgado no ano de 1886, o território foi dividido entre as cidades de Santa Maria, Júlio de Castilhos e Cachoeira do Sul (SANTIN, 1986). Posteriormente, os municípios membros começaram a se emancipar individualmente no final da década de 1950, motivados pela expectativa de melhor qualidade de vida e pela necessidade de acesso a direitos básicos como saúde, educação e melhores vias de acesso (ITAQUI, 2002). Para Santin (1986), foi com a comemoração do Centenário da Imigração Italiana no Rio Grande do Sul, em 1975, que a ex-Colônia Silveira Martins passou a ser lembrada no cenário histórico do Rio Grande do Sul. Porém, somente na década de 1990, começa o processo de retomada da ideia de conformação da ex-colônia, sob o epíteto de Quarta Colônia9.

Aproveitando-se das oportunidades de financiamento existentes voltadas para a questão de preservação ambiental, em meados de 1990 é apresentado o Projeto de Desenvolvimento Sustentável da Quarta Colônia (PRODESUS), por meio do qual os municípios reuniram-se com o objetivo de implementar ações para o desenvolvimento sustentável e potencialização dos recursos naturais e culturais da região (FROEHLICH; ALVES, 2007). Para administrar o PRODESUS, foi criado, em 1996, o Consórcio de Desenvolvimento Sustentável da Quarta Colônia (CONDESUS), buscando afirmar uma identidade territorial como suporte ao desenvolvimento regional. "O Consórcio configura uma estratégia diferenciada de conformação territorial sobrepujando as delimitações político-administrativas criadas ao longo dos processos emancipatórios" (VENDRUSCOLO, 2009, p. 67).

\footnotetext{
9 Esta denominação se deu pela colônia de Silveira Martins ter sido a quarta criada pelo Governo Imperial para os imigrantes italianos no sul do Brasil, antecedida pelas colônias Dona Isabel (Bento Gonçalves), Conde D’Eu (Garibaldi) e Fundos de Nova Palmira (posteriormente denominada de Caxias do Sul).
} 
Diversos projetos vêm sendo realizados ao longo da constituição do CONDESUS, mobilizados por um espírito de cooperação e de sentimento de territorialidade. Muitos aspectos rotineiros do território, como as práticas religiosas, a paisagem arquitetônica, os hábitos alimentares e práticas produtivas são agora ressaltados como recursos e bens culturais passando a serem acionados como sinais diacríticos em narrativas de construção e projeção identitária (FROEHLICH; ALVES, 2007; FROEHLICH; VENDRUSCOLO, 2012). A união com os municípios de colonização germânica foi vista como positiva pelos membros fundadores do CONDESUS, pois ressaltava a diversidade étnica do território, elemento importante da identidade territorial que se buscava.

Entre as ações realizadas no território com o intuito de evidenciar seus aspectos identitários, estava a criação de cartões postais retratando elementos histórico-culturais da Quarta Colônia com o objetivo de inserir o território no mercado de atração turística. Entre os cartões postais desenvolvidos, destaca-se um retratando a produção artesanal de chapéus de palha de trigo, artesanato tradicionalmente atribuído aos imigrantes italianos (Figura 2).

Figura 2 - Cartão postal da Quarta Colônia retratando a produção artesanal de chapéus de palha de trigo

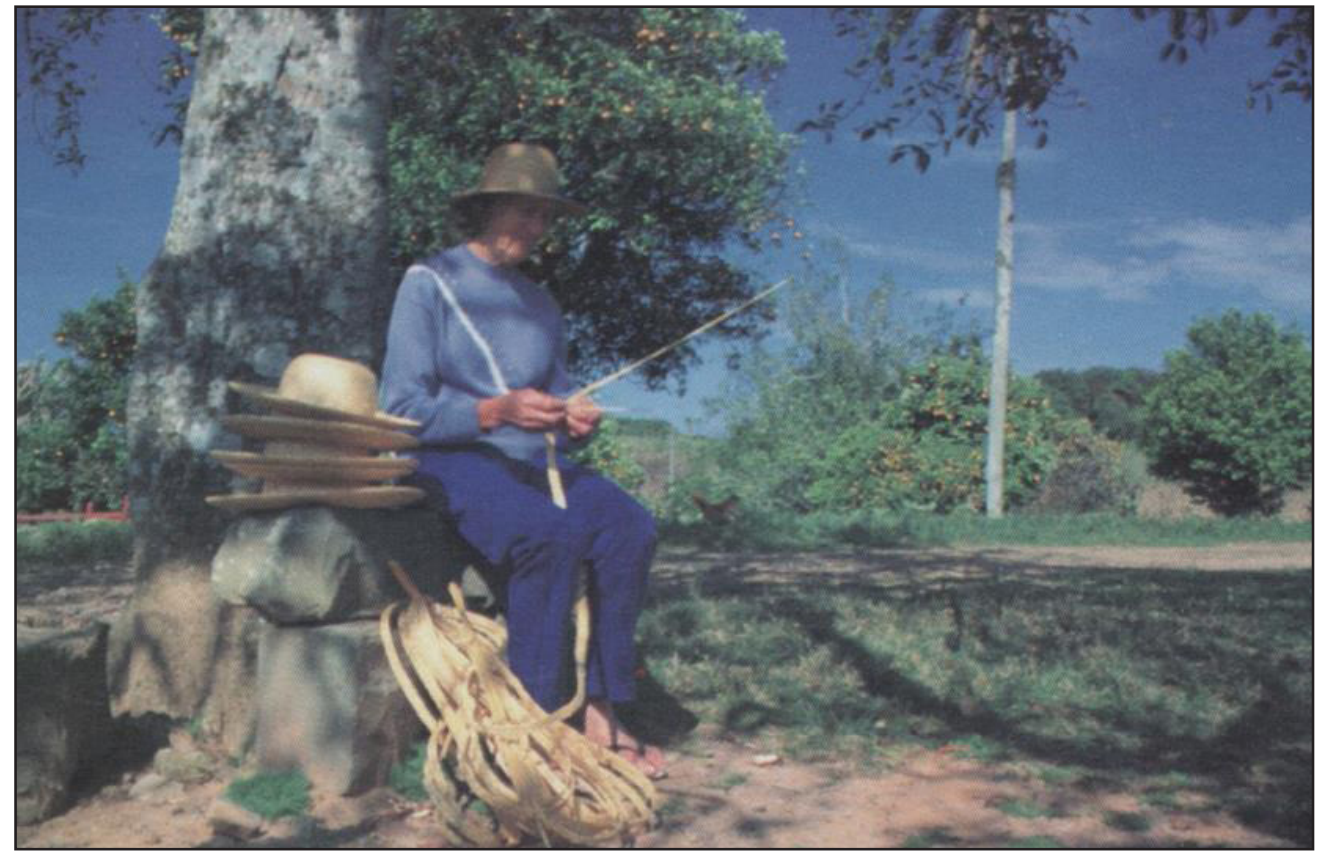

Fonte: Cartão Postal CONDESUS, fotografia de Adriana Zanoello.

Além dos cartões postais, em meados da década de 2000, o CONDESUS elaborou fôlderes de divulgação turística que ressaltavam diferentes aspectos do patrimônio existente no território, como religiosidade, gastronomia, natureza e cultura. O fôlder do tema da cultura trazia na capa a fotografia de um patrimônio edificado presente no território (a Casa Colonial em Agudo) e, na contracapa, a imagem das mãos de uma senhora fazendo crochê, técnica de artesanato comumente praticada entre os habitantes da Quarta Colônia, precedida do seguinte texto:

A cultura está presente nas ruas, nos prédios, nas praças, nas formas de ser e fazer das pessoas. Ela está em cada produto material e imaterial fruto da nossa ação. Como programa a cultura é um processo aberto, dinâmico e a sua expressão assume tantos rostos, formas, ritmos e movimentos quantos forem os seus atores. Na Quarta Colônia ela é palavra, dialetos 
alemães e italianos, artesanato, prédios, lavouras, o badalar dos sinos, a gastronomia, as danças, os cantos populares e religiosos. A cultura é uma herança renovada a cada dia e nos cabe o papel de entendê-la, protegê-la e qualificá-la como um patrimônio individual e coletivo. (Fôlder de divulgação da cultura da Quarta Colônia/CONDESUS).

O destaque dado para o artesanato no material pode ser explicado por sua importância como representante dos saberes envolvidos no conjunto da vida social dos imigrantes. "Da realidade material, esses objetos deixam lugar à realidade imaterial e imaginária, fazendo parte de uma árvore que congrega memórias de ofícios e saberes pessoais que, materializados, produziam identidades, signos sociais e étnicos" (TEDESCO, 2005, p. 89). Com o passar do tempo, muitos artefatos artesanais tradicionais no território da Quarta Colônia foram sendo substituídos por produtos industrializados, suprimindo alguns ofícios. Porém algumas técnicas, como o crochê e o tricô, permaneceram sendo praticadas de maneira atualizada: as técnicas são tradicionais, mas os motivos são contemporâneos.

Importante tentativa de mobilização e valorização do artesanato da Quarta Colônia ocorreu em 2005, quando o CONDESUS e as prefeituras locais, em parceria com o SEBRAE, promoveram uma oficina de criação de produtos, conduzida por designers consultores do SEBRAE. A oficina foi realizada em Vale Vêneto, distrito turístico de São João do Polêsine, e tinha como objetivo unir artesãos do território em torno de uma coleção que os representasse, ressaltando técnicas e temas locais (MELLO, 2016). A coleção recebeu o nome de Colônia Natal (Figura 3).

Figura 3 - Exemplares do artesanato da coleção Colônia Natal, Quarta Colônia
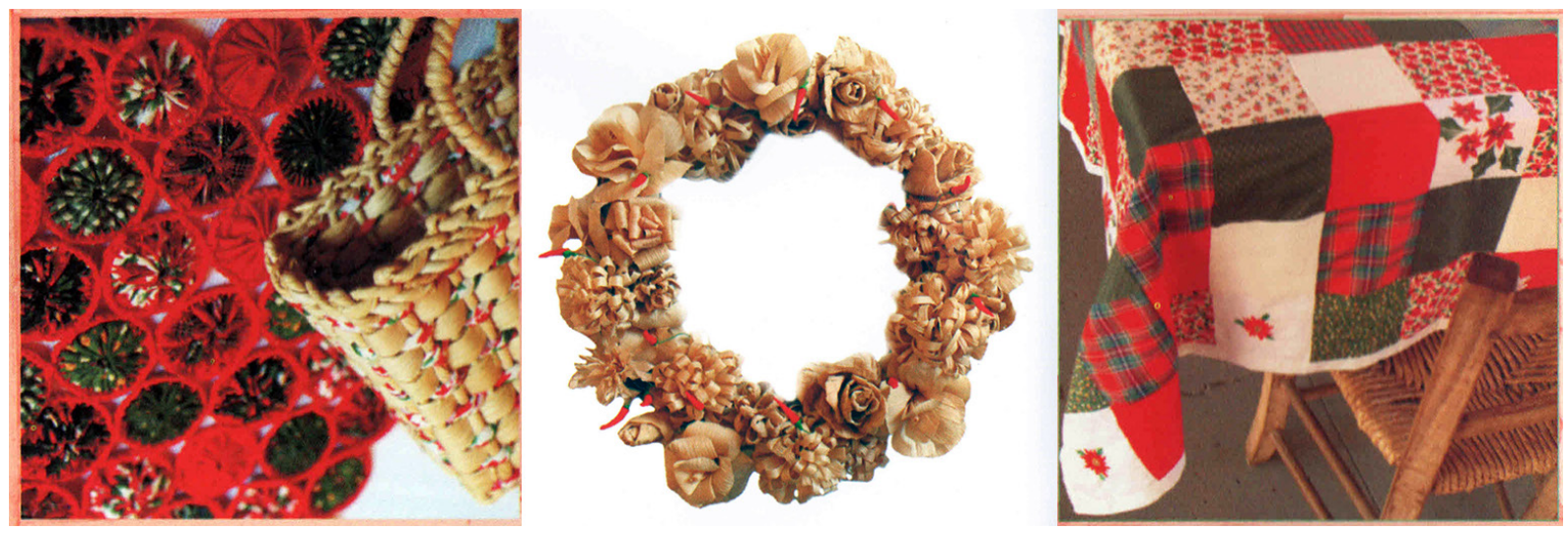

Fonte: Adaptado do fôlder de divulgação da Cultura da Quarta Colônia (CONDESUS/SEBRAE-RS, 2001).

Porém, talvez, a ação mais importante para a projeção identitária do território entre as promovidas pelo CONDESUS tenha sido o Caderno Quarta Colônia ${ }^{10}$ (CQC), publicado semanalmente entre agosto de 2006 e novembro de 2011, como encarte no jornal Diário de Santa Maria. Com circulação nas regiões Central e Fronteira-Oeste do Rio Grande do Sul, o Caderno

\footnotetext{
${ }^{10}$ A trajetória deste veículo e desta experiência e suas repercussões para a configuração da identidade territorial Quarta Colônia ainda carece de reflexões e estudos acadêmicos. Também não foram encontrados estudos de experiências semelhantes no Brasil, até mesmo porque a utilização de estratégias e veículos semelhantes parecem não ser frequentes nas abordagens territoriais do país. Em países europeus, como a Espanha, são encontrados veículos com características similares, como a Revista da ADAD (Asociación para el Desarollo de Aljarafe-Doñana, comarca da província de Sevilla) e a revista Tierra Sur, da Asociación para el Desarollo Rural de Andalucía (ARA). Porém, são poucos os estudos analisando a relação de construção e projeção de identidades territoriais e o papel da midiatização neste processo (PIPPI, 2012; FROEHLICH, 2015).
} 
destacava como atrativos turísticos do território tanto seu patrimônio material, representado pela natureza e edificações históricas, quanto o patrimônio imaterial, como as tradições locais, práticas religiosas, especificidades gastronômicas e saberes artesanais (VENDRUSCOLO et al., 2008; PIPPI, 2012, FROEHLICH, 2015). Ao descrever a iniciativa em artigo publicado no próprio Caderno Quarta Colônia, José Itaqui, então Secretário-Executivo do CONDESUS, afirmou que:

[...] o conceito de caderno, de como mostrar, abrir janelas de diálogo da Quarta Colônia com os municípios da região central. [...] o Caderno como o meio onde seriam tratadas as políticas públicas de interesse local e regional. Outro ponto importante é que o Caderno deveria ter como foco a cultura dentro de uma leitura antropológica. Que os elementos naturais e culturais fossem desenvolvidos nos seus múltiplos aspectos e recortados por um olhar público, de políticas públicas que assegurassem a sua conservação e preservação. (ITAQUI, 2010, p. 02).

A manifestação do Secretário-Executivo evidencia a intencionalidade do CONDESUS em ter no Caderno um espaço de visibilidade não apenas para as especificidades do território, mas também lançar à sociedade as discussões acerca de estratégias e ações de desenvolvimento a serem empregadas nos municípios da Quarta Colônia. A partir de seu lançamento em 2006, a publicação lançou tendências no mercado editorial regional, sendo um dos únicos espaços midiáticos onde era possível ter acesso a notícias contextuais sobre os municípios do território. Porém ele era utilizado como espaço de visibilidade de enunciados, e não de debate (VENDRUSCOLO, 2009; FROEHLICH; KEGLER, 2011; PIPPI, 2012; FROEHLICH, 2015).

A visibilidade midiática se constituiu como elemento chave para o discurso sobre o desenvolvimento do CONDESUS. A produção dos Cadernos Quarta Colônia, e mesmo de outras formas comunicativas, ilustra que o Consórcio buscou e direcionou recursos financeiros para projetos e ações voltadas para a mídia, ou seja, para formular e apoiar estratégias para melhor posicionar nos mercados uma imagem identitária coletiva do território.

\section{O ARTESANATO NO CADERNO QUARTA COLÔNIA}

Ao compreender o discurso como resultado de um jogo entre aspectos que se buscam visibilizar e outros que se buscam ignorar ou não se dar ênfase (PIPPI, 2012; FROEHLICH, 2015), infere-se que os elementos evidenciados nos fascículos do Caderno foram selecionados pelos atores envolvidos para compor a imagem que se desejava ressaltar e converter em itens a serem consumidos. Desse modo, dada à relevância contemporânea do artesanato, propiciada especialmente por seus atributos simbólicos, esta seção busca analisar, a partir de uma pesquisa documental de cunho interpretativista, como o tema foi inserido nas narrativas de construção e projeção identitária promovidas pelos 225 fascículos publicados do Caderno Quarta Colônia.

Na análise dos fascículos, foram encontradas 86 reportagens com menções ao artesanato, sendo que, em 16 delas, o município não era especificado, tratando-se do artesanato da Quarta Colônia genericamente. As demais matérias estavam divididas entre os nove municípios conforme Quadro 1. Foi possível perceber que o número de habitantes do município não tem relação direta com a divulgação de seu artesanato, já que os mais destacados foram Agudo e Ivorá, este com a menor população da Quarta Colônia e aquele com a maior. Em relação à frequência, o destaque ficou para o ano de 2007, que totalizou 22 menções ao artesanato. 
Quadro 1 - Menções ao artesanato no Caderno Quarta Colônia

\begin{tabular}{|c|c|c|c|c|c|c|c|c|c|c|c|}
\hline & $\begin{array}{l}\frac{0}{0} \\
\frac{0}{0} \\
\frac{0}{\alpha}\end{array}$ & 范 & $\begin{array}{l}\overline{0} \\
\frac{0}{0} \\
\frac{5}{5} \\
\frac{5}{0}\end{array}$ & 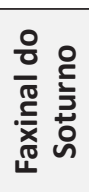 & 蛋 $\frac{\pi}{\pi}$ & 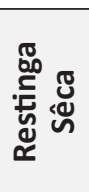 & 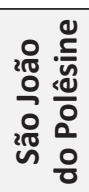 & 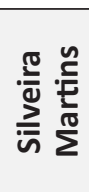 & 总 & $\begin{array}{l}\frac{\pi}{\frac{\pi}{L}} \\
\frac{0}{\frac{0}{3}} \\
\frac{0}{0}\end{array}$ & $\begin{array}{c}\text { Total/ } \\
\text { Ano }\end{array}$ \\
\hline $2006(01-22)$ & 01 & 02 & 02 & 01 & 01 & 03 & 00 & 00 & 00 & 04 & 14 \\
\hline $2007(23-17)$ & 01 & 05 & 03 & 05 & 02 & 01 & 00 & 01 & 00 & 04 & 22 \\
\hline $2008(75-126)$ & 04 & 02 & 03 & 01 & 01 & 02 & 03 & 00 & 00 & 04 & 20 \\
\hline 2009 (127-167) & 02 & 01 & 00 & 02 & 00 & 00 & 01 & 00 & 00 & 00 & 06 \\
\hline $2010(168-211)$ & 03 & 02 & 00 & 00 & 01 & 00 & 01 & 01 & 02 & 03 & 13 \\
\hline $2011(212-255)$ & 03 & 00 & 03 & 01 & 02 & 00 & 01 & 00 & 00 & 01 & 11 \\
\hline Total/município & 14 & 12 & 11 & 10 & 07 & 06 & 06 & 02 & 02 & 16 & 86 \\
\hline
\end{tabular}

Fonte: Elaborado pelos autores.

A partir da leitura das reportagens do Caderno Quarta Colônia que mencionavam o artesanato, foi possível extrair categorias de análise que auxiliaram na compreensão do papel que o artesanato desempenhou para a construção e projeção identitária do território. As consideradas mais singulares e relevantes para a presente discussão são: tradição, identidade, união e reconhecimento.

A recorrência à categoria tradição era fortemente evidenciada nos primeiros anos de publicação do fascículo. As menções ao artesanato também recebiam maior destaque, como o caso da reportagem de capa da edição número nove, 'Mãos talentosas de Pinhal Grande' (Figura 4), que apresenta uma fotografia de uma artesã produzindo um chapéu de palha de trigo. Dentro do fascículo, o texto da reportagem ressalta que 'nenhuma de suas duas filhas se interessou em dar continuidade à tradição de trançar a palha'. Apesar de a artesã ter quatro filhos, eles não foram mencionados como possíveis continuadores da técnica artesanal em questão, pois trabaIhos em palha são popularmente atribuídos a mulheres, evidenciando a divisão sexual existente no trabalho artesanal.

Figura 4 - Reportagem "Mãos talentosas de Pinhal Grande"

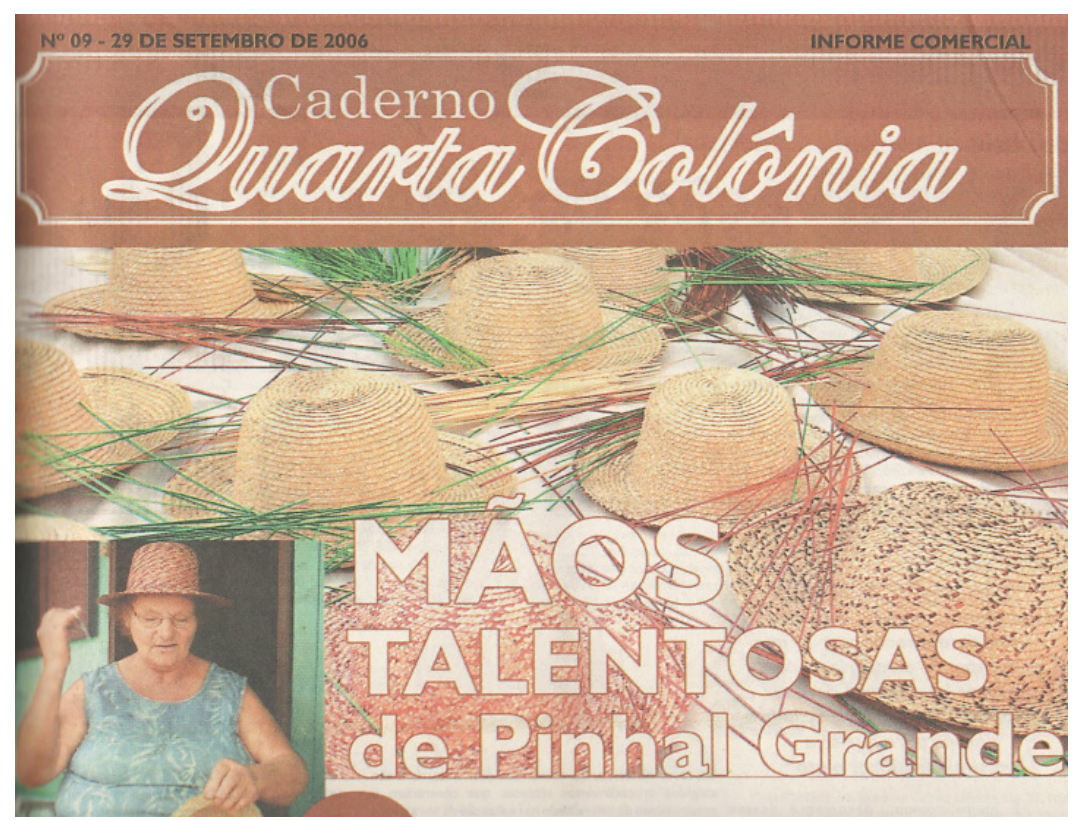

Fonte: Fascículo Caderno Quarta Colônia n. 09, publicado em 29/09/2006. 
Além da referência à palha, a reportagem em questão ressalta que os artesãos do município de Pinhal Grande trabalham com diversas técnicas artesanais e que distintas entidades atuam em prol de construir uma identidade para o artesanato. A reportagem, portanto, reforça a relevância de se submeter 0 artesanato a processos de hibridação ${ }^{11}$ para que passe a retratar uma identificação com o território, porém os esforços são dirigidos para a construção de uma identidade para o município, e não o território, enfraquecendo as estratégias de construção de uma imagem identitária territorial.

É notória a intenção do fascículo em reforçar a relevância de a tradição do trançado de palha ser acionada como sinal diacrítico na construção da imagem identitária coletiva para o território. Ao mesmo tempo, está posta uma preocupação em se ter continuidade para o artesanato no território, já que as gerações mais novas não vêm demonstrando interesse em manter vivas as tradições artesanais praticadas por seus pais ou avós.

Outras reportagens também reforçavam essa preocupação com a extinção de determinadas práticas artesanais, com destaque para a intitulada 'O último artesão de Novo Paraíso ${ }^{12}$ ', publicada em fevereiro de 2011 (Figura 5). A reportagem apresentava uma fotografia de Ademar Bonaldo e seu filho, Cristiano, junto aos objetos produzidos artesanalmente, acompanhada de um texto que alertava para a iminente extinção da prática de produzir objetos em couro artesanalmente na Quarta Colônia.

Figura 5 - O último artesão de Novo Paraíso, Nova Palma

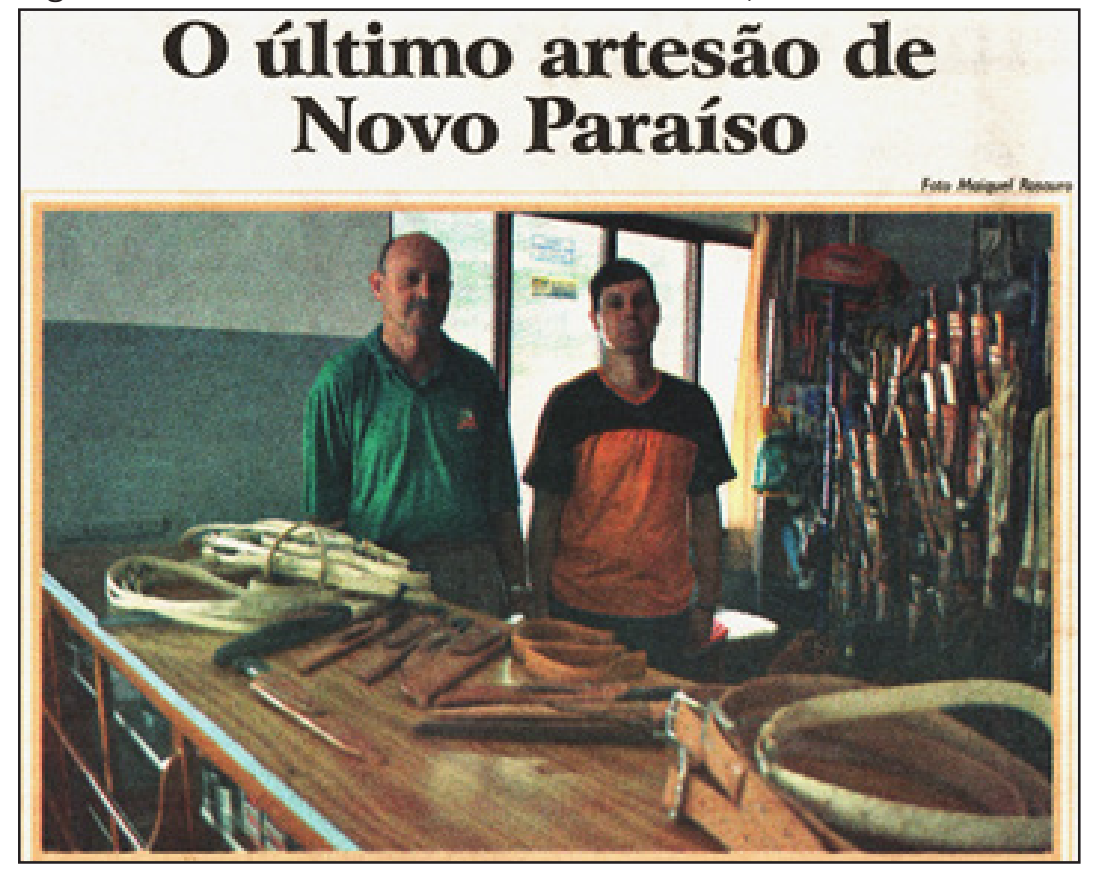

Fonte: Fascículo Caderno Quarta Colônia n. 218, publicado em 12/02/2011.

Porém, apesar de algumas técnicas artesanais estarem em iminente desaparecimento, a existência de um significativo número de artesãos na Quarta Colônia é corroborada por reportagens que anunciam a formação de associações de artesãos, reunindo artefatos artesanais

\footnotetext{
${ }^{11}$ Hibridação é aqui entendida quando estruturas ou práticas discretas, que existiam de forma separada, se combinam para gerar novas estruturas, objetos e práticas (CANCLINI, 2013, p. XIX).

${ }^{12}$ Distrito do município de Nova Palma.
} 
produzidos a partir de diferentes técnicas e motivos para comercialização conjunta. Entre os anos de 2006 e 2009, foram evidenciadas pelas reportagens as associações ou casas de artesãos dos seguintes municípios do território: Ivorá (associação fundada em fevereiro de 2006); Agudo (associação em atividade desde o ano 2000); Nova Palma (associação concebida há quase vinte anos); Restinga Sêca (espaço para o artesanato inaugurado em 2005); Pinhal Grande (associação fundada em 2007); Faxinal do Soturno (casa do artesão em atividade desde 2006); e Dona Francisca (espaço inaugurado em 2009).

A categoria união, portanto, foi uma das que se fizeram mais presentes nos fascículos analisados, com destaque para a reportagem 'Artesanato unido', de 2007, que ressaltava a participação conjunta dos artesãos dos municípios da Quarta Colônia em eventos visando promover o artesanato do território. Havia interação entre a produção artesanal dos diferentes municípios que compõem o território, e a sua visibilidade era incentivada por enunciados publicados nos fascículos do Caderno.

Outra categoria de análise que se faz recorrente nos enunciados dos fascículos publicados é o reconhecimento da distinção dos artefatos artesanais identitários, especialmente no âmbito internacional. Um exemplo é a reportagem de 2007 intitulada: 'Italianos se interessam por obra de artesão de Ivorá', que busca reforçar a singularidade do artesanato da Quarta Colônia. O texto afirma que, além de ter agradado aos italianos, as peças em madeira produzidas pelo artesão de Ivorá, que representam pontos turísticos do município e da Quarta Colônia, também são comercializadas para turistas da Argentina, Goiás e São Paulo. A reportagem, portanto, enfatiza o fato de que o artesanato identitário possui maior reconhecimento nos mercados contemporâneos.

Nesse contexto, destaca-se também a reportagem 'Artesanato de Pinhal nas passarelas do Canadá', de 2008, que apresentava a produção de crochê feita por artesãs de Pinhal Grande para a coleção de uma estilista brasileira radicada no Canadá (Figura 6). Ao dar ênfase para a exportação do artesanato produzido na Quarta Colônia, o Caderno buscava evidenciá-lo como mercadoria cuja qualidade tem reconhecimento que transcende o território.

Figura 6 - Artesanato de Pinhal nas passarelas do Canadá

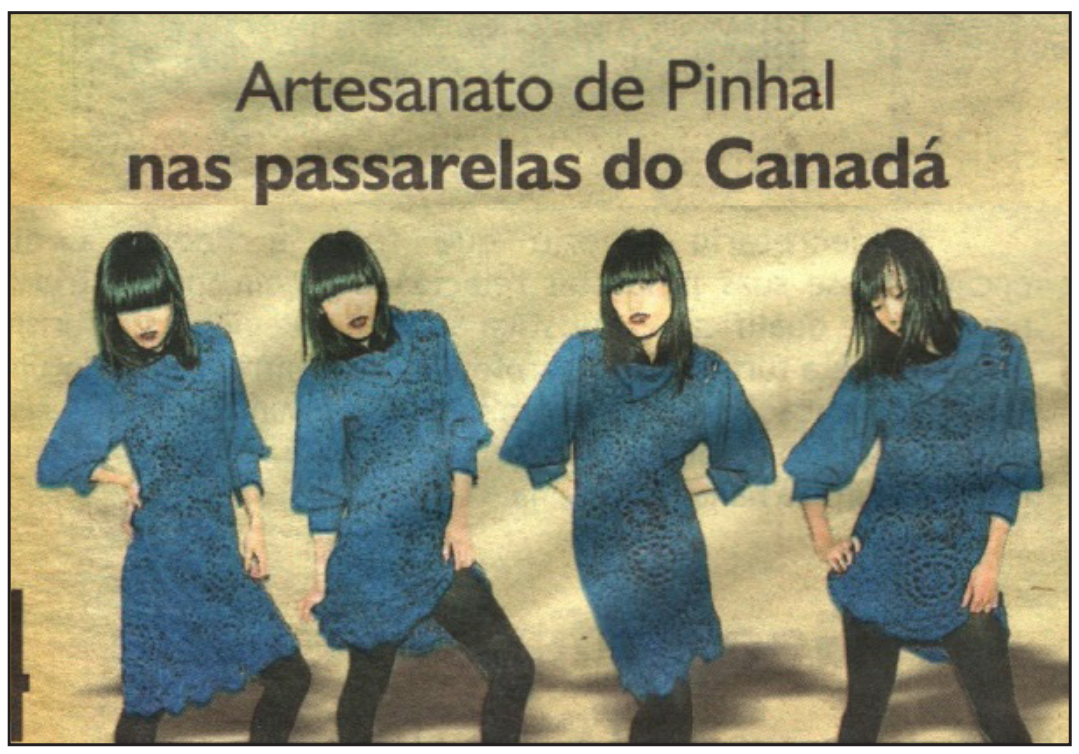

Fonte: Adaptado do Fascículo Caderno Quarta Colônia n. 110, publicado em 05/09/2008. 
O reconhecimento da prática artesanal auferido pela estilista mereceu destaque por corroborar o discurso de valorização promovido pelos atores institucionais. Além disso, o enunciado evidencia a expansão das oportunidades para o artesanato na sociedade contemporânea propiciada pelas interações que se tecem entre as especificidades locais e os processos de globalização (ORTIZ, 2009).

Porém, apesar de o artesanato ter sido citado em diversas reportagens, na grande maioria ele não era o foco do texto. As menções ao artesanato mais comumente encontradas no Caderno Quarta Colônia estavam nas reportagens sobre os eventos do território, nos quais ele aparecia comumente como uma atração de apoio à gastronomia. Em estudo similar, Vendruscolo et al. (2008) apontaram que as potencialidades gastronômicas se faziam presentes em metade dos fascículos publicados do Caderno Quarta Colônia. A ênfase midiática empreendida no aspecto gastronômico contribuiu para uma resposta positiva por parte da alteridade, de modo que a gastronomia é atualmente considerada o principal sinal diacrítico da Quarta Colônia (VENDRUSCOLO et al., 2008).

No Caderno Quarta Colônia, o recorte operacionalizado na zona de visibilidades originou enunciados que foram rearranjados para compor o discurso relacional entre identidade territorial e desenvolvimento, tornando visíveis determinadas conexões e atenuando outras. A partir do momento que tais elementos distintivos são evidenciados e integram o discurso midiático sobre o território, ele passa a ser reconhecido e consumido com base nessa enunciação (PIPPI, 2012; FROEHLICH, 2015).

Portanto a análise dos fascículos do Caderno Quarta Colônia permitiu legitimar o artesanato como parte integrante do repertório que compõe a imagem identitária coletiva do território. O seu acionamento se deu principalmente como representante de tradições trazidas pelos imigrantes para o território, evidenciando aspectos identitários de seus produtores, cuja prática resulta em união entre os artesãos de diferentes munícipios e vem recebendo crescente reconhecimento nos mercados. Porém, apesar de o artesanato ser um elemento identificador reconhecido pelos enunciados midiáticos, os esforços promovidos pelo Caderno para prover visibilidade ao setor artesanal não obtiveram um resultado tão positivo quanto o alcançado pela gastronomia. A desproporção de visibilidade midiática encontrada no Caderno entre os aspectos identitários acionados pode ter contribuído para esse fato.

\section{CONSIDERAÇÕES FINAIS}

O atual discurso do desenvolvimento tem enfatizado a abordagem territorial, dando considerável importância às relações entre os atores locais e sua capacidade de fomentar atividades econômicas baseadas na diferenciação identitária. Estratégias de visibilidade midiática são frequentemente utilizadas com o intuito de acionar os sinais diacríticos territoriais, ou seja, elementos identificadores de um grupo atribuídos e reconhecidos reciprocamente pelos seus membros, para que possam vir a compor uma imagem identitária para o território.

Nesse contexto, ressalta-se que o artesanato tem assumido crescente importância na sociedade contemporânea em razão dos atributos simbólicos que tem permitido acionar. Portanto ele pode ser acionado para que se torne expressão de identidade territorial, especialmente naqueles territórios onde estão em curso estratégias de construção e projeção identitária.

Na Quarta Colônia, o CONDESUS tem promovido ações com objetivo de afirmar uma imagem identitária coletiva para o território capaz de exercer papel estratégico nas mobilizações 
convocadas em estratégias que se tecem em nome do discurso do desenvolvimento. A divulgação e projeção dos nove municípios em um consórcio possibilitou o fortalecimento de uma identidade territorial e promoveu suas potencialidades turísticas conjuntamente.

Uma das ações que buscava dar visibilidade midiática às potencialidades do território foi a publicação do Caderno Quarta Colônia, fascículos semanalmente encartados no Jornal Diário de Santa Maria. Ao promover o turismo e a comercialização dos produtos e serviços do território, o Caderno se tornou um importante objeto de estudo para compreender o modo como o território vinha sendo divulgado nas narrativas midiáticas tecidas em nome do desenvolvimento.

$\mathrm{Na}$ análise dos 225 fascículos publicados do Caderno, foram encontradas 86 menções ao artesanato, predominantemente em reportagens que citavam a prática como uma das atrações dos eventos turísticos municipais. As matérias mais extensas sobre o artesanato orbitavam em torno do gradual desaparecimento da atividade, da sua importância enquanto representante de uma tradição colonial e da sua relevância como elemento identificador do território. Porém, apesar de ter seu potencial como sinal diacrítico reconhecido pelos enunciados midiáticos, sua visibilidade não foi acionada na mesma intensidade que outros, como a gastronomia, evidenciando o caráter seletivo dos processos de projeção identitária.

Na contemporaneidade, a midiatização é essencial para o êxito de estratégias de projeção identitária, em que a visibilidade é permanentemente disputada. Os discursos tecidos em nome do desenvolvimento são produzidos a partir de relações de poder entre os atores sociais do território que, por sua vez, definem como os enunciados serão divulgados, incluindo quais elementos serão evidenciados e quais serão relegados a um papel de coadjuvante. O artesanato da Quarta Colônia, apesar de ser um importante elemento na composição da imagem identitária coletivo do território, teve seu papel subordinado à gastronomia, que permanece sendo acionada como principal sinal diacrítico na atualidade.

\section{REFERÊNCIAS}

ABRAMOVAY, Ricardo. O futuro das regiões rurais. Porto Alegre: Ed. UFRGS, 2003.

ALBAGLI, Sarita. Território e territorialidade. In: LAGES, Vinícius Nobre et al. (Org.). Territórios em movimento: cultura e identidade como estratégias de inserção competitiva. Rio de Janeiro: Relume Dumará, 2004.

ATLAS DO DESENVOLVIMENTO HUMANO NO BRASIL. Perfil municipal. 2013. Disponível em: http://www. atlasbrasil.org.br/2013/pt/consulta. Acesso em: 15 jul. 2018.

BARICHELLO, Eugenia Mariano da Rocha. Mídia, territorialidades e sociabilidade. In: ENCONTRO DA COMPÓS, 15., 2006, Bauru, SP. Anais [...]. Bauru, SP: UNESP, 2006. Disponível em: http://www.compos. org.br/data/biblioteca_454.pdf

BARTH, Fredrik. O guru, o iniciador e outras variações antropológicas. Rio de Janeiro: Contra Capa, 2000.

BAUMAN, Zygmunt. Vida para consumo. Rio de Janeiro: Jorge Zahar Ed., 2008.

BORGES, Adélia. Design + artesanato: o caminho brasileiro. São Paulo: Terceiro Nome, 2011.

BRANDÃO, Carlos, Territórios com classes sociais, conflitos, decisão e poder. In: ORTEGA, Antônio César; ALMEIDA FILHO, Niemeyer (Org.). Desenvolvimento territorial, segurança alimentar e economia solidária. Campinas, SP: Alínea, 2007. 
CANCLINI, Nestor Garcia. Culturas híbridas: estratégias para entrar e sair da modernidade. 4. ed., 6. reimpressão. São Paulo: Editora da Universidade de São Paulo, 2013.

CASTELLS, Manuel. O poder da identidade. São Paulo: Paz e Terra, 1999.

CONDESUS/SEBRAE-RS. Cultura da Quarta Colônia. Folder, 2001.

CUNHA, Manuela Carneiro da. Antropologia do Brasil: mito, história, etnicidade. São Paulo: Brasiliense/ Editora da Universidade de São Paulo, 1986.

ESCOBAR, Arturo. El postdesarrollo como concepto y pratica social. In: MATO, Daniel (Org.). Políticas de economia, ambiente y sociedade em tiempos de globalizacion. Caracas: Universidade Central de Venezuela, 2005.

ESCOBAR, Arturo. Encountering development: the making and unmaking of the Third World. Princeton, EUA: Princeton University Press, 1995.

FAVARETO, Arilson. A abordagem territorial do desenvolvimento rural: mudança institucional ou "inovação por adição"? Estudos Avançados, São Paulo, v. 24, n. 68, p. 299-319, 2010.

FOUCAULT, Michel. Microfísica do poder. Rio de Janeiro: Graal, 1995.

FOUCAULT, Michel. História da sexualidade I (a vontade de saber). Rio de Janeiro: Graal, 1990.

FROEHLICH, José Marcos. Construção identitária e estratégias de visibilidade territorial no Rio Grande do Sul. Relatório Técnico de Pesquisa, Processo 307490/2011-4 Conselho Nacional de Desenvolvimento Científico e Tecnológico (CNPq). Brasília: MCT-CNPq, 2015.

FROEHLICH, José Marcos. Rural e natureza: a construção social do rural contemporâneo na região central do Rio Grande do Sul. 2002. 220 p. Tese (Doutorado em Ciências Sociais) - Universidade Federal Rural do Rio de Janeiro, Rio de Janeiro, 2002.

FROEHLICH, José Marcos (Org.). Desenvolvimento territorial - produção, identidade e consumo. ljuí, RS: Edunijuí, 2012.

FROEHLICH, José Marcos; VENDRUSCOLO, Rafaela. A construção social da identidade territorial Quarta Colônia- tramas e sentidos da narrativa. In: FROEHLICH, José Marcos (Org.) Desenvolvimento Territorial - Produção, Identidade e Consumo. Ijuí: Edunijuí, 2012.

FROEHLICH, José Marcos; KEGLER, Jaqueline Quincozes da Silva. Midiatização e identidade territorial: pressupostos teóricos para a análise das festividades e seus processos de mediação como construtores da identidade territorial no Brasil Meridional. Mediaciones Sociales, Madrid, n. 8, p. 97-124, 2011.

FROEHLICH, José Marcos; ALVES, Heberton F. Inocêncio. Novas identidades, novos territórios - mobilizando os recursos culturais para o desenvolvimento territorial. Extensão Rural, Santa Maria, RS, n. 14, p. 65-90, jan./dez. 2007.

HAESBAERT, Rogério. Des-territorialização e identidade: a rede gaúcha no Nordeste. Niterói, RJ: Eduff, 1997.

HALL, Stuart. A identidade cultural na pós-modernidade. Rio de Janeiro: DP\&A, 2006.

INSTITUTO BRASILEIRO DE GEOGRAFIA E ESTATÍSTICA [IBGE]. Cidades. 2014. Disponível em: http://www. cidades.ibge.gov.br. Acesso em: 14 out. 2018. 
ITAQUI, José. Os Cadernos Quarta Colônia. Caderno Quarta Colônia, n. 200, 2010.

ITAQUI, José. Quarta Colônia: inventários técnicos. Santa Maria, RS: Condesus Quarta Colônia, 2002.

KEGLER, Jaqueline Quincozes da Silva. Identidade territorial e midiatização: os sentidos identitários acionados pelas festividades da Quarta Colônia/RS. 2011. 350f. Orientador: José Marcos Froehlich. Tese de Doutorado (Extensão Rural) - Universidade Federal de Santa Maria, Santa Maria, RS, 2011.

MELLO, Carolina luva de. Território feito à mão: artesanato e identidade territorial no Rio Grande do Sul. 2016. 233f. Orientador: José Marcos Froehlich. Tese (Doutorado em Extensão Rural) - Universidade Federal de Santa Maria, Santa Maria, RS, 2016.

NEUMANN, Pedro Selvino. O impacto da fragmentação e do formato das terras nos sistemas familiares de produção. 2003. 326f. Orientador: Carlos Loch. Tese de Doutorado (Engenharia de Produção) Universidade Federal de Santa Catarina, Florianópolis, 2003.

ORTIZ, Renato. Imagens do Brasil. Revista Sociedade e Estado, Brasília, v. 28, n. 3, set./dez. 2013.

ORTIZ, Renato. Globalização: notas sobre um debate. Revista Sociedade e Estado, Brasília, v. 24, n.1, p. 231-54, jan./abr. 2009.

PAZ, Octávio. O uso e a contemplação. Revista Raiz: Cultura do Brasil, São Paulo, n. 3, 2006.

PECQUEUR, Bernard. O desenvolvimento territorial: uma nova abordagem dos processos de desenvolvimento para as economias do Sul. Raízes, Campina Grande, PB, n. 24, v. 1-2, p. 10-22, jan./ dez. 2005.

PIPPI, Joseline. Visibilidade midiática, discurso e território - em busca de uma identidade para o desenvolvimento. 2012. 300f. Orientador: José Marcos Froehlich. Tese de Doutorado (Extensão Rural) Universidade Federal de Santa Maria, Santa Maria, RS, 2012.

PROGRAMA DO ARTESANATO BRASILEIRO (PAB). Base conceitual do artesanato brasileiro. Brasília: Ministério Desenvolvimento, Indústria e Comércio Exterior, 2012.

RAFFESTIN, Claude. Por uma geografia do poder. São Paulo: Ática, 1993.

RIOS, José Arthur. Artesanato e desenvolvimento: o caso cearense. [S.I.]: CNI/SESI, 1969.

SACK, Robert. Human territoriality: its theory and history. Cambridge, UK: Cambridge University Press, 1986.

SANTIN, Silvino. A imigração esquecida. Porto Alegre: EDUCS, 1986.

SODRÉ, Muniz. Antropológica do Espelho. Por uma teoria da comunicação linear e em rede. Petrópolis, RJ: Vozes, 2002.

TEDESCO, João Carlos. O artesanato no cenário da imigração italiana. In: SULIANI, Antônio; COSTA, Frei Rovílio. Cultura italiana: 130 anos. Porto Alegre: Nova Prova, 2005.

THOMPSON, John B. A mídia e a modernidade: uma teoria social da mídia. Petrópolis, RJ: Vozes, 2008.

VENDRUSCOLO, Rafaela; FROEHLICH, José Marcos; DULLIUS, Paulo Roberto; CAVALHEIRO, Letícia. Imprimindo sabores: gastronomia e identidade territorial na Quarta Colônia - RS. In: CONGRESSO DA SOCIEDADE BRASILEIRA DE ECONOMIA, ADMINISTRAÇÃO E SOCIOLOGIA RURAL, 46., 2008, Rio Branco, 
AC. Anais [...] Rio Branco, AC, 2008. Disponível em: https://tind-customer-agecon.s3.amazonaws. com/26fbed38-1047-497f-9516-bf563ada7286? response-content-disposition=inline $\% 3 B \% 20$ filename\%2A\%3DUTF-8\%27\%27521.pdf\&response-content-type=application\%2Fpdf\&AWSAccessKeyld $=$ AKIAXL7W7Q3XHXDVDQYS\&Expires=1561407873\&Signature=pqRaN4IFMngsbmaQCtFSNXps2x0\%3D

VENDRUSCOLO, Rafaela. "Somos da quarta colônia": os sentidos de uma identidade territorial em construção. 2009. 209f. Orientador: José Marcos Froehlich. Dissertação de Mestrado (Extensão Rural) Universidade Federal de Santa Maria, Santa Maria, RS, 2009.

VERÓN, Eliséo. Esquema para el análisis de la mediatización. Diálogos de la Comunicación, Lima, Peru, 1997. Disponível em: https://comycult.files.wordpress.com/2014/04/veron_esquema_para_el_analisis_ de_la_mediatizacion.pdf

ZANINI, Maria Catarina Chitolina. Italianidade no Brasil meridional: a construção da identidade étnica na região de Santa Maria, RS. Santa Maria, RS: Editora da UFSM, 2006.

\section{Sobre os autores:}

Carolina luva de Mello-Doutora em Extensão Rural; Mestre em Engenharia de Produção; Graduada em Design. Professora adjunta do Departamento de Desenho Industrial da Universidade Federal de Santa Maria. E-mail: carolinaiuva@gmail.com, Orcid: http://orcid.org/0000-0003-0937-1230

José Marcos Froehlich - Pós-Doutor em Antropologia Social; Doutor em Ciências Sociais; Mestre em Sociologia. Professor Associado do Departamento e do Programa de Pós-Graduação em Extensão Rural. E-mail: jmarcos.froehlich@gmail.com, Orcid: http://orcid.org/0000-0001-6968-8497 